\title{
Bile acid conjugation and hepatic taurine concentration in rats fed on pectin
}

\author{
BY T. IDE, M. HORII, K. KAWASHIMA AND T. YAMAMOTO \\ Laboratory of Nutrition Chemistry, National Food Research Institute, Ministry of Agriculture, \\ Forestry and Fisheries, Tsukuba Science City, 305 Japan
}

(Received 7 March 1989 - Accepted 22 June 1989)

\begin{abstract}
A relationship between bile acid conjugation and hepatic taurine concentration was investigated in rats fed on citrus pectin. When rats were fed on the diets containing varying amounts of pectin $(10,30,60$ and $100 \mathrm{~g} / \mathrm{kg}$ dietary levels), biliary excretion of bile acids increased as the dietary levels of pectin increased. The increase was entirely due to the glycine-conjugated bile acids. The biliary excretion of taurine-conjugated bile acid was somewhat decreased as the dietary level of the fibre increased. Consequently, most of the bile acids were conjugated with glycine in rats fed on the diet containing 100 $\mathrm{g}$ pectin/kg. On the other hand, dietary cellulose $(60$ and $100 \mathrm{~g} / \mathrm{kg})$ did not affect the biliary bile acid excretions. The major proportion of bile acids in rats receiving a fibre-free diet and the diets containing cellulose were conjugated with taurine. Hepatic taurine concentrations decreased as the dietary levels of pectin, but not of cellulose, increased. Although dietary pectin $(100 \mathrm{~g} / \mathrm{kg})$ also slightly decreased the taurine concentration in the kidney, those concentrations in other non-hepatic tissues examined (heart, brain and serum) were unaffected by the dietary fibre. Supplementation of the diet containing $100 \mathrm{~g}$ pectin $/ \mathrm{kg}$ with methionine $(10 \mathrm{~g} / \mathrm{kg})$ and taurine $(10$ and $50 \mathrm{~g} / \mathrm{kg})$ strikingly increased hepatic taurine concentrations. In this situation, the conjugation of bile acid with glycine was almost abolished and taurine conjugates became abundant in the bile of these animals. It is suggested that dietary pectin mediated an increase in the biliary bile acid excretion which may have depleted the hepatic pool of taurine available for bile acid conjugation and, thus, increased glycine conjugation of bile acids.
\end{abstract}

Bile acid conjugation: Pectin: Taurine: Rat

The major proportion of bile acids in mammalian species is conjugated with glycine or taurine before being excreted via the bile into the intestinal lumen (Jacobsen \& Smith, 1968; Killenberg, 1978; Elliott, 1984). The glycine-conjugated : taurine-conjugated bile acids ratio varies from one species to another (Haslewood \& Wooton, 1950; Jacobsen \& Smith, 1968; Garbutt et al. 1971; Elliott, 1984). Man can synthesize both glycine-conjugated and taurine-conjugated bile acids, and the former generally predominate (Garbutt et al. 1971). Although the rat has long been regarded as an exclusive taurine conjugator, there is some evidence (Bergeret \& Chatagner, 1956; Hardison \& Proffitt, 1977) to indicate that this species can also synthesize considerable amounts of glycine-conjugated bile acids under particular situations where availability of taurine is limited. We have previously observed a large increase in the formation of glycine-conjugated bile acids in rats fed on pectin (Ide $\&$ Horii, 1989), and in the present study we examined the relationship between hepatic taurine concentration and bile acid conjugation in rats fed on pectin.

\section{EXPERIMENTAL}

\section{Animals and diets}

Male rats of the Wistar-Imamichi strain (4 weeks of age) were obtained from Imamichi Institute of Animal Reproduction, Ibaraki. Animals were individually housed in a room 
with controlled temperature $\left(20-22^{\circ}\right)$, humidity $(55-65 \%)$ and lighting (lights on from 07.00 hours to 19.00 hours). All the animals were fed on a commercial non-purified dict (Type NMF; Oriental Yeast Co., Tokyo) and acclimatized to our housing conditions for at least $5 \mathrm{~d}$ after arrival. The rats were then randomly divided into groups of seven to eight rats and assigned to the experimental purified diets. The basal composition of the purified diet was $(\mathrm{g} / \mathrm{kg})$ : milk casein 200 , maize oil 50, maize starch 150 , mineral mixture 35 , vitamin mixture 10 , choline bitartrate 2 and sucrose to $1 \mathrm{~kg}$. Mineral and vitamin mixtures with compositions the same as those recommended by the American Institute of Nutrition (1977) were obtained from Nihon Nosan Kogyo K.K., Tokyo. Dietary fibres (citrus pectin or cellulose) and amino acids (glycine, methionine or taurine) were added to the basal diet at the expense of sucrose. Citrus pectin containing 50-70 g methoxyl group $/ \mathrm{kg}$ (maker's statement) and crystalline cellulose made from wood pulp were obtained from Wako Pure Chemicals, Tokyo and Asahi Chemical Industry Co., Tokyo respectively. Rats were fed on the experimental diets for $25-27 \mathrm{~d}$. At the end of the feeding period, animals were anaesthetized with an intraperitoneal injection of Nembutal $(50 \mathrm{mg} / \mathrm{kg})$. The bile ducts were cannulated with PE-10 tubing and bile was allowed to drain into a test-tube cooled on ice (Sugano et al. 1983; Ide \& Horii, 1987). After $2 \mathrm{~h}$ of biliary drainage blood was withdrawn from the inferior vena cava and tissues (liver, kidney, heart and brain) were quickly excised. Faeces were collected for $3 \mathrm{~d}$ before the termination of the experimental period.

\section{Bile acid analyses}

The bile samples $(0.2 \mathrm{ml})$ were diluted with $3 \mathrm{ml} 0.5 \mathrm{M}$-potassium phosphate buffer $(\mathrm{pH} 7 \cdot 0)$ and passed through a commercial octadecylsilyl silica cartridge (Sep-Pak $\mathrm{C}_{18}$ ). The cartridge was washed with $20 \mathrm{ml}$ water and bile acids were eluted with 5-6 ml ethanol $(900$ $\mathrm{ml} / 1)$ (Ide \& Horii, 1987). Eluate $(1 \mathrm{ml})$ was applied onto a small column $(5 \times 18 \mathrm{~mm})$ of piperdinohydroxydextran gel (PHP gel, Shimazu Corp., Kyoto). The column was washed with $4 \mathrm{ml}$ ethanol $(900 \mathrm{ml} / \mathrm{l})$ and then non-conjugated, glycine-conjugated and taurineconjugated bile acids were successively eluted with $4 \mathrm{ml}$ each of ethanolic solutions $(900$ $\mathrm{ml} / 1$ ) of $0.1 \mathrm{~m}$-acetic acid, $0.2 \mathrm{M}$-formic acid and $0.3 \mathrm{~m}$-potassium acetate ( $\mathrm{pH} 6.5$ ) respectively (Ide \& Horii, 1987). Faecal bile acids were extracted with ethanol under reflux (Uchida et al. 1977). The bile acids in these extracts and samples fractionated on PHP gel were deconjugated in $1.25 \mathrm{M}-\mathrm{NaOH}\left(120^{\circ}\right.$ for $\left.6 \mathrm{~h}\right)$ and extracted with diethyl ether after an acidification of the hydrolysate with $4 \mathrm{M}-\mathrm{HCl}$ (Uchida et al. 1977). Bile acids were determined as methyl ester-acetyl ester derivatives by gas-liquid chromatography using AN-600 on gaschrom Q with nordeoxycholic acid as an internal standard (Kuriyama et al. 1979). Lithocholic, deoxycholic, hyodeoxycholic, ursodeoxycholic, cholic and $\beta$-muricholic acids were well resolved from each other in the chromatogram. However, $\alpha$-muricholic, $\omega$ muricholic and 7-ketodeoxycholic acids co-migrated and were not separated. An unidentified bile acid-presumably representing a derivative of $\beta$-muricholic acid (Kuriyama et al. 1979) - was found at varying concentrations $(0 \cdot 2-5 \%)$ in both bile and faecal samples. Faecal neutral steroids were also determined by gas-liquid chromatography using $5 \alpha$-cholestane as an internal standard (Sugano et al. 1983).

\section{Analyses for taurine and glutathione}

Tissues were homogenized with ice-cold perchloric acid $(80 \mathrm{~g} / 1 ; 3-4 \mathrm{ml} / \mathrm{g})$. The homogenates were centrifuged at $1500 \mathrm{~g}$ for $10 \mathrm{~min}$. The supernatant fractions were neutralized with $3 \mathrm{M}$-potassium carbonate. The precipitates formed were removed by centrifugation at $1500 \mathrm{~g}$ for $10 \mathrm{~min}$. The clear supernatant fractions were analysed for taurine and glutathione. Taurine in the extract was purified using a cation-anion exchange column prepared by layering $5 \times 20 \mathrm{~mm}$ Dowex $50 \mathrm{~W}-\mathrm{X} 8\left(100-200 \mathrm{mesh}, \mathrm{H}^{+}\right.$ 
form) over $5 \times 20 \mathrm{~mm}$ of Dowex 2-X8 (200-400 mesh, $\mathrm{Cl}^{-}$form) (Stephan et al. 1987). Eluate $(3 \mathrm{ml})$ was lyophilized and redissolved in $2-4 \mathrm{ml}$ water. The taurine in the sample was reacted with $o$-phthalaldehyde (Larsen et al. 1980) and analysed by high-performance liquid chromatography (Model Try Rotor-VI; Japan Spectroscopic Co. Ltd, Tokyo) using a Finepak SIL $\mathrm{C}_{18} \mathrm{~S}$ column $(4.6 \times 150 \mathrm{~mm}$; Japan Spectroscopic Co. Ltd, Tokyo) with a mobile phase of acetonitrile-water $(70: 30, \mathrm{v} / \mathrm{v} ; 12.5 \mathrm{~mm}$-sodium phosphate buffer, $\mathrm{pH}$ 6.0) at the flow rate of $0.4 \mathrm{ml} / \mathrm{min}$ and detected with a fluorimeter (Model FP-210, Japan Spectroscopic Co. Ltd, Tokyo) at $395 \mathrm{~nm}$ (excitation) and $455 \mathrm{~nm}$ (emission). Glutathione was determined enzymically by the method of Griffith (1985). The assay mixture $(1 \mathrm{ml})$ contained $0.2 \mathrm{~mm}$-NADPH, 5 mM-EDTA, $0.6 \mathrm{~mm}-5,5^{\prime}$-dithio-bis(2-nitrobenzoic acid), 1 unit yeast glutathione reductase (Oriental Yeast Co., Tokyo) and $0 \cdot 3-1 \cdot 0 \mathrm{nmol}$ glutathione in $0.1 \mathrm{M}$-potassium phosphate buffer $(\mathrm{pH} 7 \cdot 5)$.

\section{Analysis for hepatic amino acids}

Livers (approximately $1 \mathrm{~g}$ ) were homogenized with $4 \mathrm{ml}$ sulphosalicyclic acid $(60 \mathrm{~g} / \mathrm{l})$. The homogenates were centrifuged at $12500 \mathrm{~g}$ for $20 \mathrm{~min}$. The supernatant fractions were passed through ultrafiltration membrane kits (ULTRACENT-30; Tosoh Co., Tokyo). The concentrations of free amino acids in the filtrates were determined with an amino acid analyser (Model L-8500, Hitachi Koki Co., Tokyo).

\section{Lipid analyses}

Hepatic, serum and biliary lipids were extracted and purified (Folch et al. 1957). Cholesterol, triglyceride and phospholipid in the lipid extracts except for biliary and serum cholesterol were chemically determined as described previously (Ide et al. 1978). Cholesterol in the bile sample was determined enzymically (Ide et al. 1982). Serum cholesterol was determined with a commercial assay kit (Cholesterol C-test; Wako Pure Chemicals, Tokyo).

\section{Statistical analysis}

Values were analysed by one-way analysis of variance, and differences of means were inspected using Duncan's multiple range test (Duncan, 1957).

\section{RESULTS}

\section{Effect of different levels of dietary fibres on bile acid conjugation and hepatic taurine concentrations}

Rats were fed on an experimental diet free from fibre or on diets containing different levels of either cellulose $(60$ and $100 \mathrm{~g} / \mathrm{kg}$ ) or citrus pectin $(10,30,60$ and $100 \mathrm{~g} / \mathrm{kg})$ for $25-27$ $\mathrm{d}$ and bile was collected for $2 \mathrm{~h}$. Rats fed on the diets containing 60 and $100 \mathrm{~g}$ pectin $/ \mathrm{kg}$ showed slightly decreased food intake (19.5 (SE 0.6) and 18.3 (SE 0.4) g/d respectively) and growth $(7 \cdot 5$ (SE $0 \cdot 1)$ and $7 \cdot 1$ (SE $0 \cdot 2) \mathrm{g} / \mathrm{d}$ respectively) compared with the other groups (20.6-22.4 and $8 \cdot 1-8 \cdot 7 \mathrm{~g} / \mathrm{d}$ for food intake and growth respectively). Rates of bile flow tended to increase in various groups of rats fed on pectin $(0.94-1.17 \mathrm{ml} / \mathrm{h})$ compared with those fed on a fibre-free diet $(0.87 \mathrm{ml} / \mathrm{h})$. These variables in rats that received the diets containing $60(0.85 \mathrm{ml} / \mathrm{h})$ and $100 \mathrm{~g}$ cellulose $/ \mathrm{kg}(0.83 \mathrm{ml} / \mathrm{h})$ were indistinguishable from those in the rats fed on a fibre-free diet. As shown in Fig. 1, excretion of biliary bile acids increased as the dietary levels of pectin increased. The increase was entirely due to the glycine-conjugated bile acids. The amounts of taurine-conjugates excreted were somewhat decreased when the dietary levels of the fibre increased. Inclusion of cellulose (60 and 100 $\mathrm{g} / \mathrm{kg}$ diet) did not influence these variables. Phospholipid excretions tended to increase as 


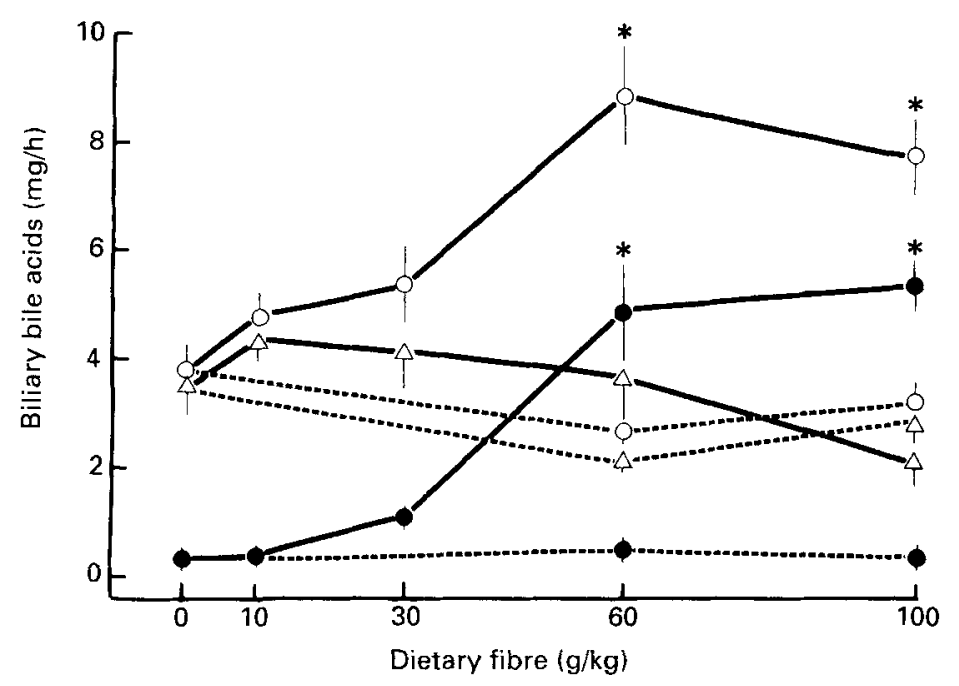

Fig. 1. Effect of varying dietary levels of pectin and cellulose on biliary bile acid excretion. Rats were fed on a purified diel free from a fibre source, or on diets containing different levels of either cellulose $(60$ and $100 \mathrm{~g} / \mathrm{kg}$ diets) or citrus pectin $(10,30,60$ and $100 \mathrm{~g} / \mathrm{kg}$ diets) for $2527 \mathrm{~d}$. Bile was collected for $2 \mathrm{~h}$. ( $O$ ) Total bile acids, ( ) glycine-conjugated bile acids, $(\triangle)$ taurine-conjugated bile acids. Rats fed on pectin $(--)$ or cellulose $(--\cdots)$. Values represent means with their standard errors for seven or eight rats. *Mean values were significantly different $(P<0.05)$ from the values for rats fed on a fibre-free diet.

the dietary levels of pectin, but not of cellulose, increased. On the other hand, cholesterol excretions were unaffected by these dietary fibres (values not shown).

The hepatic taurine concentrations, which were assayed by high-performance liquid chromatography, were found to be decreased as dietary levels of pectin, but not of cellulose, increased and the values in rats fed on the diets containing 60 and $100 \mathrm{~g}$ pectin $/ \mathrm{kg}$ approached approximately half that in those fed on a fibre-free diet (Fig. 2(a)). Neither pectin nor cellulose influenced serum taurine concentration (Fig. 2(b)). Fig. 3 shows the relationship between hepatic taurine concentration and the bile acid glycine: taurine ratio. Hepatic taurine concentrations varied widely from $1 \cdot 1$ to $4.7 \mu \mathrm{mol} / \mathrm{g}$ depending on the type of diet. However, the ratio remained low when hepatic taurine concentrations were greater than $2 \mu \mathrm{mol} / \mathrm{g}$. The ratios increased strikingly when the hepatic taurine concentrations were lower than $1.5-2.0 \mu \mathrm{mol} / \mathrm{g}$.

\section{Effect of dietary pectin and amino acids on bile acid conjugation and hepatic taurine concentrations}

In the second trial, the effects of dietary supplementation of amino acids on bile acid conjugation were studied in rats fed on the fibre-free diets and the diets containing pectin $(100 \mathrm{~g} / \mathrm{kg})$. Six different diets were given: fibre-free diet, fibre-free diet supplemented with glycine $(10 \mathrm{~g} / \mathrm{kg}), 100 \mathrm{~g}$ pectin $/ \mathrm{kg}$ diet and $100 \mathrm{~g}$ pectin $/ \mathrm{kg}$ diet supplemented with $\mathrm{L}$ methionine $(10 \mathrm{~g} / \mathrm{kg})$ or taurine $(10$ and $50 \mathrm{~g} / \mathrm{kg})$. Dietary amino acids did not influence the food intake or growth of the animals. On the other hand, these variables on the four groups of rats fed on pectin compared with those fed on the fibre-free diets supplemented with or without glycine were slightly but significantly reduced (values not shown).

As shown in Table 1, bile flows in rats fed on various pectin diets were apparently higher than those in rats fed on the two types of fibre-free diets. As dietary pectin not only 

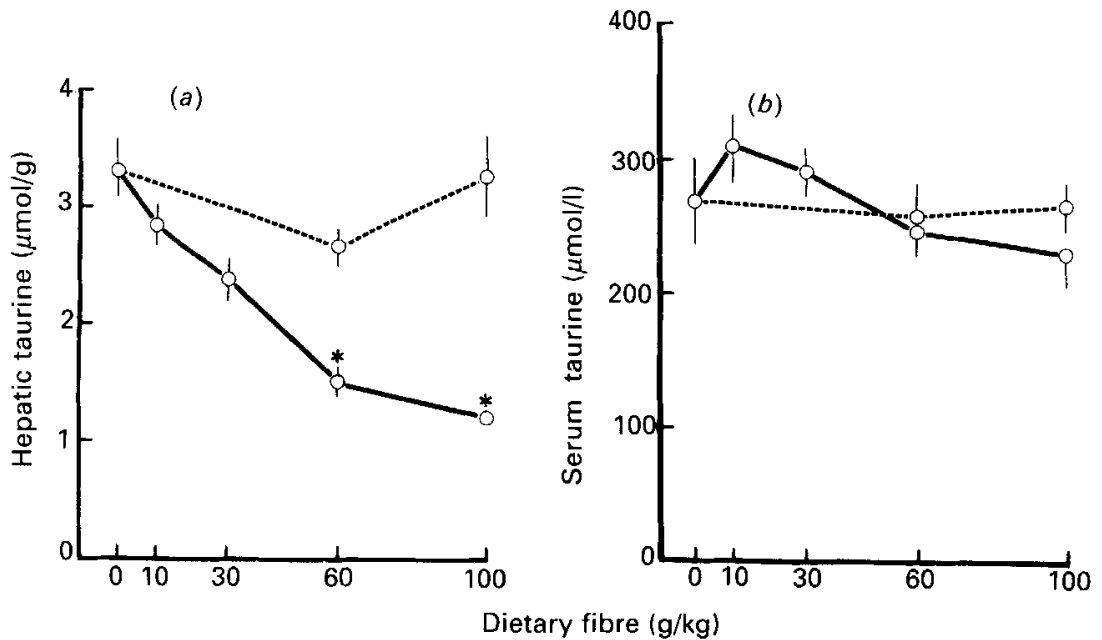

Fig. 2. Effect of varying dietary levels of pectin and cellulose on (a) hepatic and $(b)$ serum taurine concentrations. Rats were fed on a purified diet free from a fibre source, or on diets containing different levels of either cellulose ( 60 and $100 \mathrm{~g} / \mathrm{kg}$ diets) or citrus pectin $(10,30,60$ and $100 \mathrm{~g} / \mathrm{kg}$ diets) for 25-27 d. Bile was collected for $2 \mathrm{~h}$. Rats fed on pectin $(-)$ or cellulose $(--)$. Values represent means with their standard errors for seven or eight rats. * Mean values were significantly different $(P<0.05)$ from the values for rats fed on a fibre-free diet.

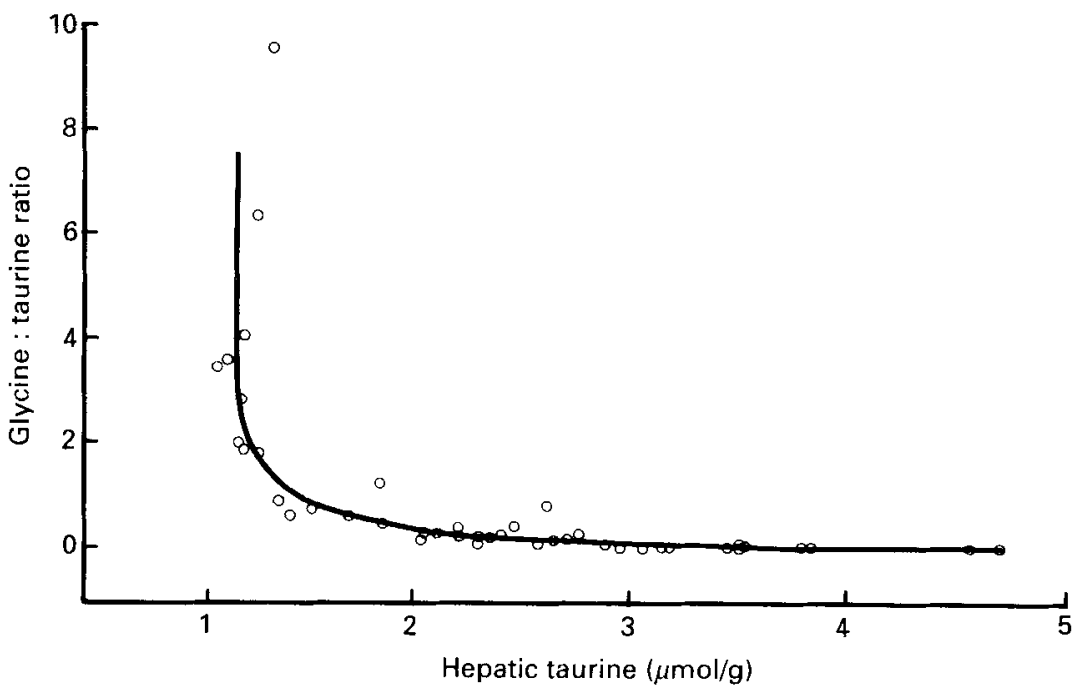

Fig. 3. Relationship between bile acid glycine: taurine ratio and hepatic taurine concentration in rats fed on a fibrefree diet and diets containing varying levels of either cellulose or pectin. Rats were fed on a purified diet free from a fibre source, or on diets containing different levels of either cellulose (60 and $100 \mathrm{~g} / \mathrm{kg}$ diets) or citrus pectin ( 10 , 30,60 and $100 \mathrm{~g} / \mathrm{kg}$ diets) for $25-27 \mathrm{~d}$. Bile was collected for $2 \mathrm{~h}$.

increased the concentration of biliary bile acids but also enhanced the bile flow of the animals, hourly excretion of bile acids in rats fed on various pectin diets more than doubled compared with bile acid excretion in animals fed on fibre-free diets. The dietary amino acids tested did not influence these variables in rats fed on fibre-free and pectin diets. The bulk of biliary bile acids in rats fed on a fibre-free diet was conjugated with taurine. 


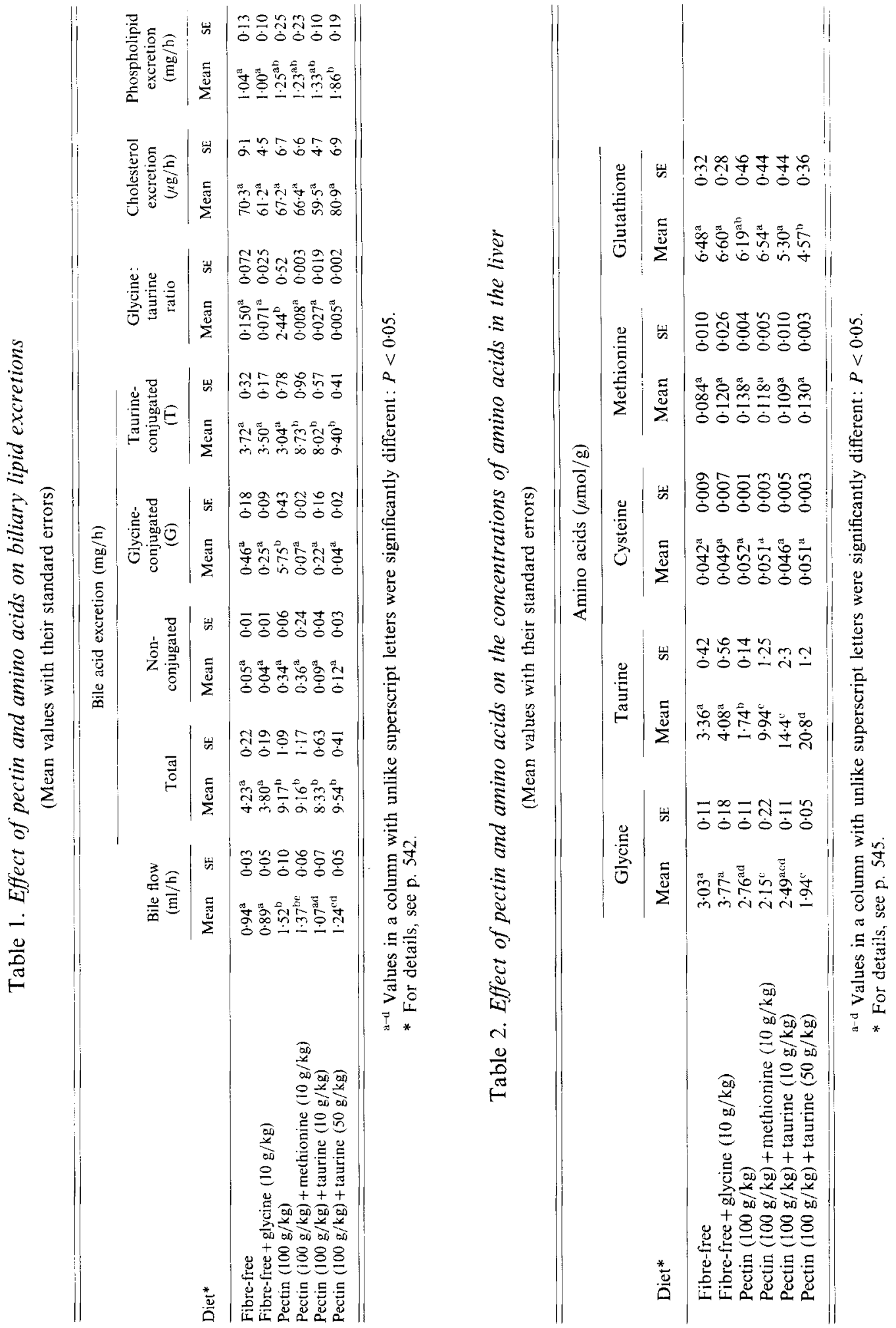


Supplementation with glycine did not increase the excretion of the bile acids conjugated with glycine. Dietary pectin strikingly increased the excretion of glycine conjugates; however, that of the taurine conjugates tended to decrease. As a consequence, the bile acid glycine: taurine ratio was considerably increased by dietary fibre. The glycine conjugates in rats fed on pectin represented only a minor proportion of the total biliary bile acids when the diet was supplemented with 10 or $50 \mathrm{~g}$ taurine $/ \mathrm{kg}$ or with $10 \mathrm{~g}$ methionine $/ \mathrm{kg}$. Consequently, the glycine: taurine ratios in these groups became even lower than those in rats fed on the two types of fibre-free diets. Biliary phospholipid excretions in rats fed on various pectin diets compared with those in animals fed on the fibre-free diets tended to increase. The value was the highest in rats fed on the pectin diet containing $50 \mathrm{~g}$ taurine $/ \mathrm{kg}$. No significant differences in the rates of biliary cholesterol excretion were observed among the various groups.

Table 2 summarizes the hepatic concentrations of amino acids. The values, except for glutathione, were measured with an amino acid analyser. Hepatic glutathione concentrations (sum of the values of reduced and oxidized forms) were measured enzymically (Griffith, 1985). The values in Table 2 are represented as the reduced form. Although hepatic taurine concentrations were also measured by high-performance liquid chromatography, the values presented in Table 2 are those obtained with an amino acid analyser. Hepatic glycine concentrations in rats fed on a fibre-free diet were appreciably higher than those in rats fed on four different types of diets containing $100 \mathrm{~g}$ pectin $/ \mathrm{kg}$. Statistically significant differences were found between rats fed on a fibre-free diet and those fed on pectin diets supplemented with methionine $(10 \mathrm{~g} / \mathrm{kg})$ or taurine $(50 \mathrm{~g} / \mathrm{kg})$. When a fibre-free diet was supplemented with glycine, the hepatic concentration of the amino acid increased significantly. The value in this group was also significantly higher than those in rats fed on various pectin diets. Consistent with the previous experiment (Fig. 2), dietary pectin significantly reduced the taurine concentration in the liver. Supplementation of a fibre-free diet with glycine tended to increase the value. On the other hand, not only dietary taurine but also methionine strikingly increased the concentration of taurine in rats fed on pectin diets. Similar results were obtained when taurine concentrations were assayed by high-performance liquid chromatography (values not shown). The concentrations of cysteine and methionine were much lower than those of glycine and taurine, and the values were not influenced even when the pectin diet was supplemented with methionine $(10 \mathrm{~g} / \mathrm{kg})$. Hepatic concentrations of glutathione, which serves as a reservoir for cysteine (Higashi et al. 1977; Tateishi et al. 1977), were approximately the same for rats fed on a fibre-free diet and a pectin diet without added amino acids. Supplementation of a fibre-free diet with glycine or of a pectin diet with methionine did not influence the values. On the other hand, supplementation of a pectin diet with 10 or $50 \mathrm{~g}$ taurine $/ \mathrm{kg}$ slightly decreased the value.

The concentrations of taurine and glutathione in extrahepatic tissues and serum were determined (Table 3). Taurine was analysed by high-performance liquid chromatography. The taurine concentration in the kidneys of rats fed on pectin was significantly reduced as compared with those in animals fed on the two types of fibre-free diets. However, the extent of the decrease was apparently attenuated as compared with that in the liver (cf. Table 2). The values in the other tissues and serum were only slightly and not significantly decreased by dietary pectin. Although additions to the pectin diet of methionine or taurine increased taurine concentrations in extrahepatic tissues and serum, the responses were again attenuated as compared with alterations in the liver. There were no significant differences in the glutathione concentrations in heart, kidney and brain among the various groups.

Table 4 summarizes the faecal steroid excretions as well as lipid concentrations in serum and liver. Weights of faeces excreted were approximately doubled in various groups of rats fed on the diets containing pectin as compared with those fed on fibre-free diets. 

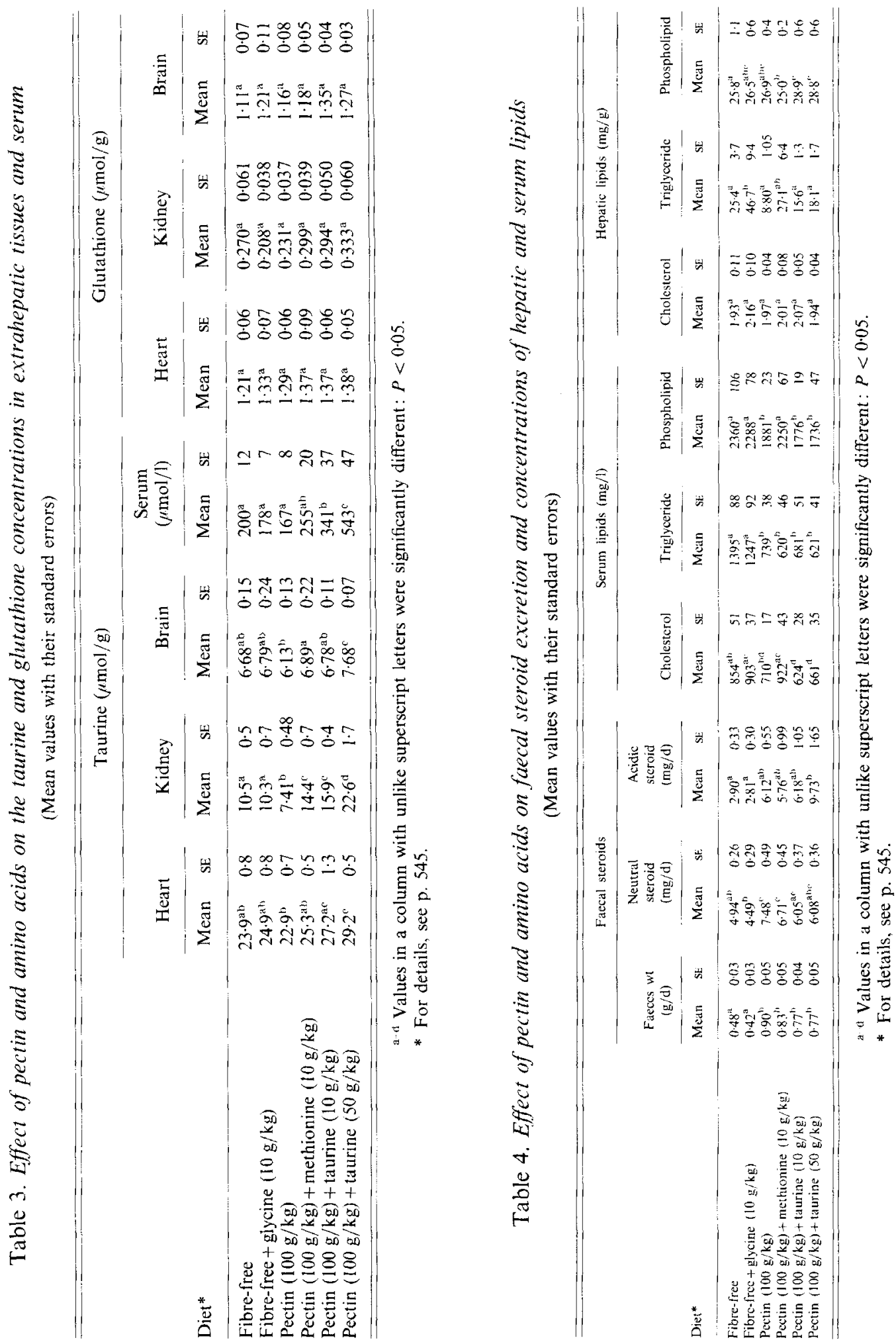
Supplementation with amino acids in no way influenced the measured variables in either rats fed on the fibre-free diets or those fed on pectin diets. Dietary pectin significantly increased the daily excretion of neutral steroids. Supplementation with glycine of the fibrefree diet did not affect this variable. On the other hand, dietary methionine and taurine tended to decrease the values in rats fed on pectin. The amounts of bile acid excreted in faeces of rats fed on the pectin diet containing $50 \mathrm{~g}$ taurine $/ \mathrm{kg}$ were significantly higher than those of the animals fed on two types of fibre-free diets. Although the differences were not statistically significant, the values in the other groups were also considerably higher than those in the two groups of rats fed on the fibre-free diets. Supplementation of the fibrefree diet with glycine did not affect the variable. On the other hand, addition of $50 \mathrm{~g}$ taurine $/ \mathrm{kg}$ to a pectin diet tended to increase bile acid excretion. Supplementation of a pectin diet with $10 \mathrm{~g}$ methionine $/ \mathrm{kg}$ or $10 \mathrm{~g}$ taurine $/ \mathrm{kg}$ was ineffective in this respect.

Serum lipid concentrations in rats fed on various pectin diets, except for the diet containing $10 \mathrm{~g}$ methionine $/ \mathrm{kg}$, were lower than those in animals fed on the two types of fibre-free diets. Methionine significantly increased the concentrations of serum lipids except for triglyceride in rats fed on the pectin diet. Dietary glycine did not affect the serum lipid levels of rats fed on a fibre-free diet. Hepatic cholesterol concentrations were approximately the same for the various groups. Although the differences were not statistically significant due to the large variations within groups, the triglyceride concentrations of rats fed on a fibre-free diet without glycine appeared to be higher than those of rats fed on the various pectin diets, except for the diet containing methionine. Supplementation of a fibre-free diet with glycine further increased the triglyceride value. Dietary methionine and taurine also tended to increase the triglyceride value of rats fed on the pectin diet. Hepatic phospholipid concentrations of rats fed on the pectin diets containing 10 and $50 \mathrm{~g}$ taurine $/ \mathrm{kg}$ were appreciably higher than those of the other groups.

\section{DISCUSSION}

It has long been recognized that rats conjugate bile acids almost exclusively with taurine and it has been thought that significant amounts of glycine conjugates were synthesized only under non-physiological conditions in which taurine synthesis was seriously impaired (Bergeret \& Chatagner, 1956; Sturman, 1973). However, recent studies indicate that rats synthesize considerable amounts of glycine conjugates under situations where bile acid or cholesterol metabolism is modified (Hardison \& Proffitt, 1977; Yamanaka et al. 1985; Ide \& Horii, 1989). We have previously demonstrated a large increase in the amount of glycine conjugates in biliary and lumen bile acids in rats fed on the diet containing $100 \mathrm{~g}$ pectin $/ \mathrm{kg}$ (Ide \& Horii, 1989). In the same study, we observed that dietary cholesterol $(5 \mathrm{~g} / \mathrm{kg})$ is also effective in increasing glycine conjugation in rats. We have confirmed the increase in glycine conjugation of bile acids of rats fed on pectin in the present study (Fig. 1 and Table 1).

Availability of taurine in the liver appeared to be a factor in the regulation of the partition of bile acids between glycine and taurine in mammals, including humans (Bergeret \& Chatagner, 1956; Sjövall, 1959; Truswell et al. 1965; Jacobsen \& Smith, 1968; Spaeth \& Schneider, 1974; Hardison \& Proffitt, 1977; Vessey, 1978; Stephan et al. 1981). In the present study, a dietary pectin-mediated increase in glycine conjugation (Fig. 1 and Table 1) was associated with a considerable decrease in hepatic taurine concentration (Fig. 2 and Table 2). Moreover, the large increases in hepatic taurine concentration associated with dietary methionine and taurine (Table 2) accompanied decreased glycine conjugation and increased taurine conjugation in rats fed on the diet containing pectin. Thus, it is very probable that the decreased availability of taurine in the liver of rats fed on pectin is responsible for the increased formation of glycine-conjugated bile acids in these animals. 
Consistent with the observations made by others (Sjövall, 1959; Bengmark et al. 1964), the extents of glycine conjugation of bile acids did not depend on dietary availability nor the hepatic concentrations of glycine (Tables 1 and 2). Thus, the availability of glycine could not be regarded as a determinant to alter the bile acid conjugation either with glycine or taurine. It is doubtful whether the availability of taurine is the only determinant in the partition of bile acids between glycine and taurine. The enzyme of bile acid conjugation has been purified to homogeneity from the livers of rat (Killenberg \& Jordan, 1978) and bovine (Vessey, 1979). These studies both indicated that there is one enzyme for bile acid conjugation. With the rat enzyme, the $K_{m}$ value for glycine was approximately forty times higher than that for taurine (Killenberg \& Jordan, 1978). In this situation, the concentration of taurine relative to glycine should be extremely low in order to conjugate appreciable amounts of bile acid with glycine. This was not necessarily the case in rats fed on pectin where the hepatic taurine concentration was only $35 \%$ lower than the glycine concentration (Table 2). These results may indicate the existence of a distinct pool of amino acids for bile acid conjugation, and dietary pectin may reduce the taurine concentration below that for glycine in this pool. The fact that the bile acid glycine: taurine ratio did not increase proportionally as the hepatic taurine concentration decreased, but rather increased strikingly when the amino acid concentration was decreased to the observed levels (Fig. 2), may support this concept. The distinct hepatic taurine pool for bile acid conjugation presumably could not be depleted until the amino acid concentration became lower than a certain value. Alternatively, there is the possibility that dietary pectin induced a distinct enzyme for bile acid conjugation specific for glycine which has not hitherto been identified in rat liver. Further studies are required to draw a definite conclusion.

Although the mechanism by which dietary pectin decreased the hepatic taurine concentration (Tables 2 and 3 ) is not necessarily clear at present, it is plausible that pectin mediated an increase in biliary bile acid excretion, thus depleting the hepatic taurine pool available for bile acid conjugation. A similar situation has been demonstrated in perfused rat liver. When rat liver was perfused continuously with cholic acid, the bile acid mediated an increase in biliary bile acid excretion associated with decreased hepatic taurine concentration and increased glycine conjugation of the bile acids (Hardison \& Proffitt, 1977).

As sulphur amino acids are biologically toxic (Benevenga, 1974; Weinstein et al. 1988), these amino acids are rapidly converted to taurine when a large amount of sulphur amino acids is fed to the rats (Hosokawa et al. 1988). As a consequence, hepatic concentration and urinary excretion of taurine greatly increased, while hepatic concentration of the sulphur amino acids remained unchanged in these animals (Tateishi et al. 1977; Kohashi et al. 1978; Hosokawa et al. 1988). In the present study, dietary methionine failed to affect hepatic concentrations of sulphur amino acids or of glutathione, which serves as a reservoir for cysteine (Higashi et al. 1977; Tateishi et al. 1977), in rats fed on pectin (Table 2). In contrast, the sulphur amino acid greatly increased the hepatic concentration of taurine. Thus, the enzyme system in rats fed on pectin appeared to convert methionine to taurine efficiently in the situation in which the availability of sulphur amino acids was increased. Milk casein, the protein source currently employed for the experimental diets, is relatively deficient in sulphur amino acids (Hosokawa et al. 1988). Thus, the sulphur amino acid content of the diet may be too low to synthesize taurine in the situation where the demand for the compound to conjugate bile acid is greatly increased, as observed in rats fed on pectin. Dietary methionine and taurine increased taurine conjugation and decreased glycine conjugation of biliary bile acids, while total bile acid excretion was unchanged in rats fed on pectin (Table 1). Thus, the availability of taurine for bile acid conjugation could not be regarded as a factor to affect biliary bile acid excretion. 
As the physicochemical properties of glycine-conjugated and taurine-conjugated bile acids are considerably different (Tamesue et al. 1973; Armstrong \& Carey, 1987), alterations in the relative amounts of these bile acids would be expected to modify the processes of lipid absorption in the small intestine and thus alter the serum and tissue lipid concentrations. Although the studies made in experimental animals (Herrmann, 1959; Yamanaka et al. 1986) as well as humans (Darling et al. 1985; Thompson et al. 1987) support this view, the reported results appear to be rather inconclusive and controversial. In the present study, neither analyses of hepatic and serum lipids nor faecal excretion of steroids (Table 4) led to any definite conclusion regarding the physiological significance of alterations of the bile acid glycine: taurine ratio in modulating lipid metabolism in rats.

The present study confirmed the increased synthesis of glycine-conjugated bile acids in rats fed on pectin. It is suggested that pectin mediated an increase in biliary bile acid excretion, depleted the hepatic pool of taurine available for bile acid conjugation and thus increased the glycine conjugation of bile acids.

The authors wish to thank Dr Joseph A. Ontko of the Oklahoma Medical Research Foundation for his critical evaluation of the manuscript. Dr Kiyoshi Hayashi of the National Food Research Institute kindly measured hepatic amino acids with an amino acid analyser.

\section{REFERENCES}

American Institute of Nutrition (1977). Report of the American Institute of Nutrition Ad Hoc Committee on standards for nutritional studies. Journal of Nutrition 107, 1340-1348.

Armstrong, M. J. \& Carey, M. C. (1987). Thermodynamic and molecular determinants of sterol solubilities in bile salt micells. Journal of Lipid Research 28, 1144-1155.

Benevenga, N. J. (1974). Toxicities of methionine and other amino acids. Journal of Agricultural and Food Chemistry 22, $2-9$

Bengmark, S., Ekdahl, P.-H. \& Olsson, R. (1964). Effect of taurine and glycine treatment on the conjugation of bile acids in partially hepatectomized rats. Acta Chirurgica Scandinavica 128, 180-185.

Bergeret, B. \& Chatagner, F. (1956). Influence d'une carence en vitamin B $_{6}$ sur la teneur en acides tauro-conjugués et glyco-conjugués de la bile du rat. Biochimica et Biophysica Acta 22, 273-277.

Darling, P. B., Lepage, G. \& Leroy, C. (1985). Effect of taurine supplements on fat absorption in cystic fibrosis. Pediatric Research 19, 578-582.

Duncan, D. B. (1957). Multiple range tests for correlated and heteroscedastic means. Biometrics 13, $164-176$.

Elliott, W. E. (1984). Metabolism of bile acid in liver and extrahepatic tissues. In Sterols and Bile Acids, pp. 303-329 [H. Danielsson and J. Sjövall, editors]. Amsterdam: Elsevier Science Publishers B.V.

Folch, J., Lee, M. \& Sloane-Stanley, G. H. (1957). A simple method for the isolation and purification of total lipides from animal tissues. Journal of Biological Chemistry 226, 497-509.

Garbutt, J. T., Lack, L. \& Tyor, M. P. (1971). Physiological basis of alterations in the relative conjugation of bile acids with glycine and taurine. American Journal of Clinical Nutrition 24, 218-228.

Griffith, O, W. (1985). Glutathione and glutathione disulphide. In Methods of Enzymatic Analysis, 3rd English ed., pp. 521-529 [H. U. Bergmeyer, J. Bergmeyer and M. Grabl, editors]. Deerfield Beach, FL: VCH Publishers.

Hardison, W. G. M. \& Proffitt, J. H. (1977). Influence of hepatic taurine concentration on bile acid conjugation with taurine. American Journal of Physiology 232, E75-E79.

Haslewood, G. A. D. \& Wooton, V. (1950). Comparative studies of 'bile salts'. 1. Preliminary survey. Biochemical Journal 47, 584-597.

Herrmann, R. G. (1959). Effect of taurine, glycine and $\beta$-sitosterol on serum and tissue cholesterol in the rat and rabbit. Circulation Research 7, 224-227.

Higashi, T., Tateishi, N., Naruse, A. \& Sakamoto, Y. (1977). A novel physiological role of liver glutathione as a reservoir of L-cysteine. Journal of Biochemistry 82, 117-124.

Hosokawa, Y., Niizeki, S., Tojo, H., Sato, I. \& Yamaguchi, K. (1988). Hepatic cysteine dioxygenase activity and sulfur amino acid metabolism in rats: possible indicators in the evaluation of protein quality. Journal of Nutrition 118, 456461 .

Ide, T. \& Horii, M. (1987). A simple method for the extraction and determination of non-conjugated and conjugated luminal bile acids in rats. Agricultural and Biological Chemistry 51, 3155-3157.

Ide, T. \& Horii, M. (1989). Predominant conjugation with glycine of biliary and luminal bile acids in rats fed on pectin. British Journal of Nutrition 61, 545-557. 
Ide, T., Okamatsu, H. \& Sugano, M. (1978). Regulation by dietary fats of 3-hydroxy-3-methylglutaryl-coenzyme A reductase in rat liver. Journal of Nutrition 108, 601-612.

lde, T., Oku, H. \& Sugano, M. (1982). Reciprocal responses to clofibrate in ketogenesis and triglyceride and cholesterol secretion in isolated rat liver. Metabolism 31, 1065-1072.

Jacobsen, J. G. \& Smith, L. H. Jr (1968). Biochemistry and physiology of taurine and taurine derivatives. Physiological Reviews 48, 424-511.

Killenberg, P. G. (1978). Measurement and subcellular distribution of choloyl-CoA synthetase and bile acid-CoA: amino acid $N$-acyltransferase activities in rat liver. Journal of Lipid Research 19, 24-31.

Killenberg, P. G. \& Jordan, J. T. (1978). Purification and characterization of bile acid-CoA: amino acid $N$ acyltransferase from rat liver. Journal of Biological Chemistry 235, 1005-1010.

Kohashi, N., Yamaguchi, K., Hosokawa, Y., Kori, Y., Fujii, O. \& Ueda, I. (1978). Dietary control of cysteine dioxygenase in rat liver. Journal of Biochemistry 84, 159-168.

Kuriyama, K., Ban, Y.\& Nakashima, T. (1979). Simultaneous determination of biliary bile acids in rat: Electron impact and ammonia chemical ionization mass spectrometric analyses of bile acids. Steroids 34, 717-728.

Larsen, B. R., Grosso, D. S. \& Chang, S. Y. (1980). A rapid method for taurine quantitation using high performance liquid chromatography. Journal of Chromatographic Sciences 18, 233-236.

Sjövall, J. (1959). Effects of dietary glycine and taurine on bile acid conjugation in man. Proceedings of the Society for Experimental Biology and Medicine 100, 676-678.

Spaeth, D. G. \& Schneider, D. L. (1974). Taurine synthesis, concentration, and bile salt conjugation in rat, guinea pig. and rabbit. Proceedings of the Society for Experimental Biology and Medicine 147, 855-858.

Stephan, Z. F., Armstrong, M. J. \& Hayes, K. C. (1981). Bile lipid alterations in taurine-depleted monkeys. American Journal of Clinical Nutrition 34, 204-210.

Stephan, Z. F., Lindsey, S. \& Hayes, K. C. (1987). Taurine enhances low density lipoprotein binding. Internalization and regulation by cultured Hep G2 cells. Journal of Biological Chemistry 262, 6069-6073.

Sturman, J. A. (1973). Taurine pool sizes in the rat: Effects of vitamin B-6 deficiency and high taurine diet. Journal of Nutrition 103, 1566-1580.

Sugano, M., Ide, T., Kohno, M., Cho, Y.-J. \& Nagata, Y. (1983). Biliary and fecal steroid excretion in rats fed partially hydrogenated soybean oil. Lipids 18, 186-192.

Tamesue, N., Inoue, T. \& Juniper, K. (1973). Solubility of cholesterol in bile salt-lecithin model systems. Digestive Disease 18, 670-678.

Tateishi, N., Higashi, T., Naruse, A., Nakashima, K., Shiozaki, H. \& Sakamoto, Y. (1977). Rat liver glutathione: possible role as a reservoir of cysteine. Journal of Nutrition 107, 51-60.

Thompson, G. N., Robb, T. A. \& Davidson, G. P. (1987). Taurine supplementation, fat absorption, and growth in cystic fibrosis. Journal of Pediatrics 111, 501-506.

Truswell, A. S., McVeigh, S., Mitchell, W. D. \& Bronte-Stewart, B. (1965). Effect in man of feeding taurine on bile acid conjugation and serum cholesterol levels. Journal of Atherosclerosis Research 5, 526-533.

Uchida, K., Nomura, Y., Kadowaki, M., Takeuchi, N. \& Yamamura, Y. (1977). Effect of dietary cholesterol on cholesterol and bile acid metabolism in rats. Japanese Journal of Pharmacology 27, 193-204.

Vessey, D. A. (1978). The biochemical basis for the conjugation of bile acid with either glycine or taurine. Biochemical Joumal 174, $621-626$.

Vessey, D. A. (1979). The co-purification and common identity of cholyl CoA:glycine- and cholyl CoA:taurine$N$-acyltransferase activities from bovine liver. Journal of Biological Chemistry 254, 2059-2063.

Weinstein, C. L., Haschemeyer, R. H. \& Griffith, O. W. (1988). In vivo studies of cysteine metabolism: use of Dcysteinesulfinate, a novel cysteinesulfinate decarboxylase inhibitor to probe taurine and pyruvate synthesis. Journal of Biological Chemistry 263, 16568-16579.

Yamanaka, Y., Tsuji, K. \& Ichikawa, T. (1986). Stimulation of chenodeoxycholic acid excretion in hypercholesterolemic mice by dietary taurine. Journal of Nutritional Science and Vitaminology 32, $287 \ldots 296$.

Yamanaka, Y., Tsuji, K., Ichikawa, T., Nakgawa, Y. \& Kawamura, M. (1985). Effect of dietary taurine and taurocyamine on biliary glycine/taurine ratio and cholesterol and bile acid metabolisms. Sulfur Amino Acids $\mathbf{8}$, $209-214$ 